\section{Detection of abnormalities is not synonymous with patient benefit}

We appreciate Gravel and colleagues' efforts to develop a clinical decision rule that successfully identifies skull fractures among young children with mild head trauma and no indication for head computerized tomography (CT). ${ }^{1}$ We wonder, however, if these skull fractures warrant diagnosis and, specifically, if affected children benefit from their detection. Isolated skull fractures have been suggested as an example of overdiagnosis, the accurate detection of an abnormality from which a patient does not experience net benefit., ${ }^{2,3}$

Follow-up outcome data, such as receipt of surgical repair, are needed to assess the possibility of patient benefit, but they are not included in the present study. Other studies have found that clinical deterioration and surgical intervention are rare among well-appearing children with isolated skull fractures. ${ }^{4,5}$ Even when repair is performed among this cohort, the impetus is generally cosmetic. If growing skull fractures are the concern (which, as the authors concede, are exceedingly uncommon), then the important research question becomes how to best predict these specific fractures rather than how to predict skull fractures in general.

Faced with an unclear benefit of testing, we must consider the potential harms. How often did skull fracture findings trigger CT scans, for which there is an added risk of malignancy? Though isolated skull fractures do not necessarily warrant routine hospitalization, studies have demonstrated that most children with this finding are indeed admitted to hospital. ${ }^{5}$ Parental anxiety and guilt resulting from the news that their young child has a skull fracture is an additional concern.

Improving the means to detect abnormities is a timeless objective in medicine, but we must pair this work with efforts to determine whether children receive more benefit than harm as a result of increased or improved diagnosis.
Eric R. Coon MD

University of Utah, Salt Lake City, Utah

Alan R. Schroeder MD

Santa Clara Valley Medical Center,

San Jose, Calif.

\section{References}

1. Gravel J, Gouin S, Chalut D, et al. Derivation and validation of a clinical decision rule to identify young children with skull fracture following isolated head trauma. CMAJ 2015;187:1202-8.

2. Coon ER, Quinonez RA, Moyer VA, et al. Overdiagnosis: how our compulsion for diagnosis may be harming children. Pediatrics 2014;134:1013-23.

3. Schroeder AR, Redberg RF. The harm in looking. JAMA Pediatr 2013;167:693-5.

4. Schutzman SA, Barnes P, Duhaime AC, et al. Evaluation and management of children younger than two years old with apparently minor head trauma: proposed guidelines. Pediatrics 2001;107: 983-93.

5. Powell EC, Atabaki SM, Wootton-Gorges S, et al. Isolated linear skull fractures in children with blunt head trauma. Pediatrics 2015;135:e851-7.

CMAJ 2016. DOI:10.1503/cmaj.1150077

\section{Public health benefits from legalizing cannabis: both sides of the coin}

Although Spithoff and colleagues mention some benefits of legalizing cannabis, they provide more details about the potential harms. The positives are limited to reducing stigma and "realization of therapeutic benefits."1

It may be difficult for physicians viewing cannabis through the lens of addiction to see any silver lining from legalization. However, there are both individual and public health benefits that should be balanced against possible harms. The first and most immediate benefit is that patients who use cannabis for therapeutic purposes will no longer fear legal sanctions.

Both the US and Canada are currently dealing with an increase in addiction and death from fentanyl, oxycodone and other opiates. Two large studies have shown about a $25 \%$ decrease in deaths from opiate overdose associated with the legalization of medical cannabis and the availability of dispensaries. ${ }^{2,3}$ The recent COMPASS study found that the use of cannabis for chronic pain has a reasonable safety profile and that patients often used it as a substitute for other more harmful drugs, such as opiates, NSAIDS (nonsteroidal anti-inflammatory drugs) and alcohol. ${ }^{4}$ Harm reduction experts have also expressed concerns that professional societies are jeopardizing patient health by requiring a much higher standard for the prescribing of cannabis over the prescribing of opioids. ${ }^{5}$

Legalization of cannabis would remove research blockades to begin proper study of cannabidiol. This compound is not associated with a "high," is not known to be addictive and has antiseizure, antianxiety and antipsychotic properties. ${ }^{6}$ Up to this point, proper study of cannabidiol and other cannabinoids has been restricted by their criminalized status.

\section{Ian Mitchell, MD, RCPSC}

Department of Emergency Medicine,

University of British Columbia, Kamloops, $\mathrm{BC}$

\section{References}

1. Spithoff S, Emerson B, Spithoff A. Cannabis legalization: adhering to public health best practice. CMAJ 2015; 187:1211-6.

2. Powell D, Pacula RL, Jacobson M. Do medical marijuana laws reduce addictions and deaths related to pain killers? Cambridge, MA: National Bureau of Economic Research; 2015 Jul. Available: www.nber.org/papers/w21345 (accessed 2015 Oct. 15).

3. Bachhuber MA, Saloner B, Cunningham CO, et al. Medical cannabis laws and opioid analgesic overdose mortality in the United States, 1999-2010. JAMA Intern Med 2014;174:1668-73.

4. Ware MA, Wang T, Shapiro S, et al; COMPASS study team. Cannabis for the management of pain: assessment of safety study (COMPASS). J Pain 2015;16:1233-42.

5. Lake S, Kerr T, Montaner J. Prescribing medical cannabis in Canada: Are we being too cautious? Can J Public Health 2015;106:e328- 30

6. The biology and potential therapeutic effects of cannabidiol. National Institute on Drug Abuse. Available: www.drugabuse.gov/about-nida/legislative -activities/testimony-to-congress/2015/biology -potential-therapeutic-effects-cannabidiol (accessed 2015 Sept. 5).

Go to cmaj.ca for the full-text version of this letter.

CMAJ 2016. DOI:10.1503/cmaj.1150076

\section{Letters to the editor}

In submitting a letter, you automatically consent to having it appear online/in print. All letters accepted for print will be edited for space and style. See www.cmaj.ca for full versions and competing interests. 